\title{
Neoconservadorismo com Roupagem Alternativa: a Nova CEPAL dentro do Consenso de Washington
}

\author{
Marcelo Dias Carcanholo*
}

\begin{abstract}
Resumo: Este trabalho procura fazer uma análise crítica da proposta da Nova CEPAL para a retomada do crescimento e desenvolvimento na América Latina. O objetivo é demonstrar que essa proposta, na verdade, não propõe a ruptura com as reformas neoliberais, apostando em um gerenciamento eficaz dessas reformas. Argumenta-se apenas no que se refere à reforma de abertura externa das economias, que isso implica manter e acentuar os desequilibrios estruturais que conformam a restrição externa ao crescimento das economias da região. Sendo assim, uma verdadeira alternativa deveria, como pré-condição, rechaçar e reverter essas reformas.
\end{abstract}

Palavras-chave: Nova CEPAL, Neoliberalismo, Consenso de Washington.

Abstract: This work search an critical analysis of the New ECLAC proposal for the retaking of growth and development in Latin America. The purposes is to demonstrate than this proposal, in fact, do not proposes the neoliberal reforms rupture, betting on the efficient management of these reforms. The paper argues that it takes to pronounce the external structural disequilibrium which conforms the external restriction to growth of the latin american economies. In such case, a real alternative need, as a condition, to refute and return these neoliberal reforms.

Keywords: New ECLAC, Neoliberalism, Washington Consensus.

JEL Classification: O53, O16, O11.

\section{Introdução}

A Comissão Econômica para a América Latina (CEPAL) nasceu como uma agência ligada à ONU, no sentido de pensar e difundir a teoria do desenvolvimento com base nas especificidades da região.

No plano teórico, uma de suas principais contribuições foi a crítica à teoria (neo) clássica do comércio internacional, assentada na hipótese das vantagens comparativas. Segundo o pensamento clássico

* E-mail: mdcarc@uol.com.br.

Recebido em 28 de junho de 2007. Aceito em 29 de novembro de 2007. 
da CEPAL, ${ }^{1}$ a tendência à deterioração dos termos de troca, desde 1870, implicaria transferências de renda da periferia do sistema capitalista em direção ao centro da economia mundial.

Segundo o diagnóstico desse pensamento, os países industrializados possuiriam um setor secundário importante e uma demanda dinâmica de trabalho, o que proporcionaria uma tendência a aumentos salariais e incentivos à tecnologia poupadora de trabalho. Essa incorporação de progresso técnico não levaria à redução dos preços, ${ }^{2}$ o que explicaria a deterioração dos termos de troca, em detrimento dos preços dos produtos exportados pela periferia.

Por outro lado, os países periféricos apresentariam um baixo desenvolvimento do setor industrial e não seriam capazes de produzir tecnologia, levando a uma dinâmica econômica de reduzida produtividade e baixa oferta de empregos. $\mathrm{O}$ resultado seriam o alto desemprego e a redução dos salários. Dessa forma, o excesso de mão-de-obra na produção para exportação - essencialmente agrícola - levaria a uma expansão da oferta com redução dos preços internacionais das exportações. ${ }^{3}$

A teoria tradicional tende a reduzir o comportamento dos preços a especificidades na elasticidade da demanda pelos produtos. $\mathrm{Na}$ interpretação estruturalista da CEPAL, ainda que essas elasticidades possam cumprir um papel, não são causas suficientes para explicar a deterioração dos termos de troca. ${ }^{4}$ Para Furtado (1986), a deterioração dos termos de troca teria como causa principal a rigidez estrutural inserida em uma divisão internacional do trabalho, cuja dinâmica não permitiria que o comércio exterior possuísse um papel de promoção de transformações estruturais. Ao contrário, essa dinâmica tenderia a aprofundar a heterogeneidade estrutural.

A permanência da divisão internacional do trabalho, calcada na hipótese das vantagens comparativas, só aprofundaria a brecha entre as economias centrais e as periféricas, perpetuando o subdesenvolvimento

1 Como pensamento clássico da CEPAL, entenderemos o arcabouço analítico com perspectiva crítica que caracterizou, principalmente, as décadas de 50 e 60 o pensamento desta comissão, dentro do que se convencionou chamar desenvolvimentismo.

2 Na explicação primeira de Prebisch (1949), a razão básica estaria na maior organização trabalhista nas economias centrais, que criariam uma maior resistência a reduções salariais na fase descendente do ciclo e forte pressão por elevações salariais na fase ascendente, assim como na estrutura produtiva concentrada que impediria a queda dos preços dos produtos industriais nessa fase.

3 Trata-se de algo similar ao tradicional argumento da oferta ilimitada de mão-de-obra.

4 "As assimetrias no comportamento da demanda (lei de Engel, concorrência de sintéticos etc.) somente têm significação quando dão origem a estruturas de produção de graus distintos de flexibilidade. Seria errôneo, entretanto, transformar as assimetrias de demanda em causas suficientes das diferenças de flexibilidade estrutural" (FURTADO, 1986, p. 170). 
das últimas. Este último, portanto, estaria relacionado com o grau de dependência externa das economias periféricas, responsável último pelos seus problemas estruturais.

A proposta do pensamento clássico da CEPAL incluía medidas corretivas no plano do comércio internacional, aliadas a uma política/estratégia econômica pró-industrialização, baseada no processo de substituição de importações, que promovesse o desenvolvimento e o fim, ou pelo menos redução, da dependência em relação aos mercados internacionais. Essa proposta desenvolvimentista fornecia ao Estado um papel central na medida em que este seria o responsável pelo planejamento desse desenvolvimento e por implementar essa estratégia/ política econômica adequada ao esforço industrializante. ${ }^{5}$

A proposta alternativa da CEPAL para superar o subdesenvolvimento era a industrialização planejada e implementada por ações estatais - em detrimento dos sinais de mercado, como pregava, e continua pregando, o pensamento ortodoxo - ou seja, tratava-se de uma proposta nacional-desenvolvimentista.

Dentro do pensamento crítico, essa proposta da CEPAL sofreu muitas críticas, ${ }^{6}$ seja porque desenvolvimento e subdesenvolvimento seriam tratados apenas por uma diferenciação quantitativa, não percebidos como uma relação dialética de oposição e unidade, seja porque a concepção de Estado fosse neutra, como se este estivesse fora da sociedade, alheio às contradições de classe, e possuísse uma racionalidade própria, ou ainda porque a industrialização não resolveria os problemas do subdesenvolvimento e da dependência, apenas conferindo-lhes outras formas de manifestação.

De uma forma ou de outra, é inegável que o pensamento clássico da CEPAL faz parte da tradição crítica ao pensamento ortodoxoconservador. Para este, o subdesenvolvimento é, em primeiro lugar, uma condição originada por problemas, insuficiências e incapacidades dos próprios países subdesenvolvidos. Em segundo lugar, e em conseqüência do anterior, trata-se, portanto, de implementar boas políticas (sic), que, invariavelmente, significam o estabelecimento de uma economia de mercado, com pouca intervenção estatal, sem restrições aos fluxos internacionais de produtos, serviços e capitais, aceitando a divisão internacional do trabalho segundo a "lei" das vantagens comparativas.

5 Segundo Bielschowsky (2000, p. 16), "seu (da CEPAL) princípio normativo é a idéia da necessidade da contribuição do Estado ao ordenamento do desenvolvimento econômico nas condições da periferia latino-americana".

6 Estas e outras críticas podem ser encontradas em Caputo e Pizarro (1970), Marini (1992), Marini (1994) e Sotelo Valencia (2005). 
Independente de todas as críticas que possam ser feitas à proposta clássica da CEPAL, tratava-se de um pensamento crítico ao conservadorismo e à ortodoxia. $\mathrm{O}$ que pretendemos demonstrar aqui é que o pensamento da Nova CEPAL, a partir dos anos 90 do século passado, renega essa característica crítica e passa a inserir-se dentro do pensamento ortodoxo, não podendo, portanto, constituir-se como alternativa ao desastre promovido pelo neoliberalismo na região. ${ }^{7}$

\section{Pensamento Contemporâneo da CEPAL}

A inflexão de rumos na CEPAL pode ser percebida a partir de trabalho oficiais da Comissão, organizados principalmente por Fernando Fajnzylber. O principal desses documentos é de 1990, Transformação Produtiva com Eqüidade: a tarefa prioritária do desenvolvimento da América Latina e do Caribe nos anos 90. Embora as questões centrais ainda sejam a apropriação do progresso técnico e a desigualdade relativa da renda nacional das economias periféricas, o tratamento dessas questões, as propostas de superação do subdesenvolvimento e o posicionamento frente ao papel das reformas neoliberais é o que nos permitirá enquadrar a Nova CEPAL dentro do posicionamento ortodoxo representado pelo Consenso de Washington. ${ }^{8}$

\subsection{Reformismo conservador da Nova CEPAL}

A implementação das reformas neoliberais na América Latina, a partir dos anos 90 do século passado, ao contrário das promessas de seus defensores, provocou aumento das desigualdades, acentuação das restrições ao crescimento e maiores instabilidades e crises

7 Esta tese também pode ser encontrada em outros trabalhos como Almeida Filho (2003) e Osorio (2004). O que se pretende aqui é ir além, e especificar essa guinada da CEPAL rumo à ortodoxia no que diz respeito ao processo de abertura externa. Nesse sentido, não concordamos com Almeida Filho (2003) quando este assume a idéia de que as reformas neoliberais, dentro do Consenso de Washington, teriam um papel que se resumiria à estabilização macroeconômica. Acreditamos que, para além disso, essas reformas e, em específico o processo de abertura externa, jogam um papel decisivo no pensamento ortodoxo sobre crescimento e desenvolvimento.

8 Ao contrário do que pensa Bielschowsky (2000), não é a permanência dos temas o que dá coesão teórica e metodológica a qualquer tipo de pensamento, mas a forma como são abordados. Subdesenvolvimento, pobreza, distribuição de renda, heterogeneidade, restrições externas, não são temáticas exclusivas do pensamento crítico. Trabalha-las a partir de uma concepção teórica e metodológica crítica e, portanto, não ortodoxa, é que faz de um pensamento ser crítico, alternativo. De alguma forma, Rodriguez et al. (1995) fazem algo parecido. 
econômicas na região. $\mathrm{O}$ posicionamento com respeito às reformas neoliberais tornou-se obrigatório para qualquer perspectiva que se proponha alternativa na região. ${ }^{9}$

Para Bielschowsky (2000, p. 63):

A CEPAL dos anos 1990 logrou posicionar-se com grande habilidade entre os dois extremos. Não colocou-se contra a maré das reformas, ao contrário, em tese tendeu a apóia-las, mas subordinou sua apreciação do processo ao critério da existência de uma "estratégia" reformista que pudesse maximizar seus benefícios e minimizar suas deficiências a médio e longo prazos.

Em primeiro lugar, uma perspectiva teórica que pretenda posicionar-se entre dois extremos inconciliáveis - defender as reformas pró-mercado como estratégia de desenvolvimento, ou argumentar que essas reformas só aprofundam os problemas estruturais das economias dependentes - não estaria, na verdade, posicionando-se, mas abstendo-se de algo que é imperativo no debate a respeito das estratégias de desenvolvimento. Em segundo lugar, não é verdade que a Nova CEPAL assuma uma posição intermediária nos dois extremos, já que ela explicitamente apóia as reformas pró-mercado. Que a Nova CEPAL defenda um "retoque" nas reformas, isso não a posiciona ao lado das perspectivas críticas ao neoliberalismo, ao contrário, como veremos adiante, isso é característica da atual fase do pensamento ortodoxo, dentro do que ele mesmo chama de pósConsenso de Washington.

Segundo os próprios defensores do pensamento neoestruturalista ${ }^{10}$ da Nova CEPAL, seriam duas as características principais desse arcabouço. Por um lado, a primazia na definição do desenvolvimento seria do mercado; por outro, o Estado teria um papel de regulação e estímulo das decisões privadas, fator responsável, em última instância, pelo crescimento e desenvolvimento. Para Ramos (1997), isso tornaria específico o pensamento da Nova CEPAL frente

9 A própria ortodoxia sente necessidade de reformular suas idéias - sem alteração do conteúdo - em virtude do fracasso das reformas neoliberais. O curioso é que essa reformulação da ortodoxia se dá seja pela afirmação de que as reformas não tiveram tempo de maduração, isto é, não houve tempo suficiente para que seus resultados aparecessem (BAER e MALONEY, 1997), seja porque as reformas não teriam sido aplicadas corretamente e/ou integralmente (KUCZYNSKI e WILLIAMSON, 2004). De uma forma ou de outra, a ortodoxia é incapaz de reconhecer que as reformas neoliberais aprofundam os problemas estruturais das economias dependentes e periféricas.

${ }_{10}$ Terminologia que eles mesmos empregam, como em Ramos (1997). 
à visão clássica da CEPAL, e também frente à proposta neoliberal da ortodoxia. ${ }^{11} \mathrm{O}$ quadro 1 resume a idéia.

Quadro 1. Orientação do desenvolvimento e papel do Estado

\begin{tabular}{|l|r|r|}
\hline & Desenvolvimento para fora & Desenvolvimento para dentro \\
\hline Estado passivo & Ortodoxia (neoliberal) & \\
\hline Estado ativo & Nova CEPAL (neoestruturalismo) & Visão cepalina passada \\
\hline
\end{tabular}

Fonte: Ramos (1997).

Segundo esse autor, nenhuma perspectiva teórica defenderia um viés do desenvolvimento para o mercado interno, isto é, com restrições ao grau de abertura externa, ao mesmo tempo em que o Estado fosse uma instituição meramente passiva no processo. O neoliberalismo defenderia a abertura externa das economias periféricas e o Estado mínimo, enquanto o pensamento clássico da CEPAL seria totalmente oposto, com restrições ao grau de abertura da economia e privilégio do mercado interno, ao mesmo tempo em que o Estado planejaria e direcionaria a estratégia de desenvolvimento.

Por outro lado, o neoestruturalismo da Nova CEPAL defende a abertura da economia como forma de obter uma competitividade não espúria, via baixos salários, mas pela via do mercado, com incentivo à concorrência externa e o estímulo ao aumento da produtividade interna, aliada a um Estado que possuísse um papel ativo, regulando os mercados e priorizando as decisões privadas.

A forma reducionista, para dizer o mínimo, como diferentes estratégias de desenvolvimento são aqui tratadas deve ser criticada, em especial a visão implícita segundo a qual Estado e Mercado são antitéticos dentro da dinâmica capitalista. Mesmo assim, ela serve para nossos propósitos em dois sentidos. No primeiro, demonstra a necessidade imperativa que a Nova CEPAL tem de se diferenciar da ideologia neoliberal, presente no Consenso de Washington. Como veremos adiante, em que pese todo o esforço de seus autores, isso não é conseguido. Além disso, uma observação mais apurada do quadro 1 já nos permitiria chegar a essa conclusão. O que diferencia, segundo seus próprios defensores, o pensamento da Nova CEPAL

${ }^{11} \mathrm{O}$ mesmo é feito em Rodriguez et al. (1995. 101) quando concluem o artigo assinalando que "já se indicou que a nova estratégia de desenvolvimento da CEPAL está relacionada com seu pensamento originário, e que pode ser vista como uma complementação do mesmo, demandada e induzida por novos tempos e realidades. Também se insinuou que ela se configura como diversa do conjunto de recomendações de longo prazo próprias do enfoque neoliberal". 
da ortodoxia neoliberal, dado que os dois defendem o desenvolvimento para fora? A resposta está no papel do Estado. O neoliberalismo defenderia a passividade deste frente aos sinais de mercado, enquanto o Estado da Nova CEPAL seria ativo. Mas, o que se entende por Estado ativo? Não se trata mais de direcionar, planejar, implementar uma política econômica que contrarie os sinais do mercado, mas de um Estado que regule os mercados, no sentido que garanta o melhor ambiente institucional para as decisões privadas, a livre iniciativa e o estímulo à concorrência, ou seja, permita ao mercado a primazia na definição do desenvolvimento. Se isto é um papel ativo para o Estado, dentro do neoestruturalismo, o que restaria para diferencia-lo do pensamento ortodoxo neoliberal?

Com essa perspectiva, a estratégia proposta pela Nova CEPAL é a da "Transformação Produtiva com Eqüidade", ou da "Reforma das Reformas". ${ }^{12}$ A idéia é aproveitar as oportunidades oferecidas hoje em dia dentro da maior competitividade internacional. O que se tem aqui é uma espécie de pragmatismo conservador. Como a economia mundial vive uma fase em que os países implementam reformas pró-mercado, em especial de aberturas de suas economias frente à concorrência internacional, não se deve retroceder nas reformas, nem muito menos rechaça-las. Deve-se toma-las como um dado e, a partir disso, buscar elementos de política para aproveitar as oportunidades e minimizar as mazelas sociais. A transformação produtiva só seria possível com incorporação do progresso técnico, que não implicasse em competitividade espúria (baixos salários), e isto só poderia ser obtido por intermédio da ampliação do ambiente concorrencial promovida pela nova etapa de globalização:

Segundo se induz, o progresso técnico, contínuo e intenso, tende ademais a universalizar-se, através da intensificação da concorrência internacional; essa intensificação acompanha uma tendência paralela à globalização da economia mundial (RODRIGUEZ et al., 1995, p. 84). ${ }^{13}$

Sendo assim, Reforma das Reformas não significa retroceder, nem romper, com as reformas neoliberais, mas aceita-las como um parâmetro, implementando políticas sociais compensatórias para minimizar os efeitos sociais deletérios que elas podem produzir.

${ }_{12}$ As duas expressões são utilizadas para sintetizar a agenda da Nova CEPAL. A primeira dá título ao documento já citado (CEPAL, 1990), enquanto que a nomenclatura Reforming the reforms para essa agenda pode ser encontrada em Ocampo (1999) e Ffrench-Davis (1999).

${ }^{13}$ Essa noção de incorporação dinâmica do progresso técnico, assim como de seus efeitos sobre a estrutura econômica, em função da concorrência inter-capitais, é muito próxima da abordagem neo-schumpeteriana, como reconhecido explicitamente por esses autores. 
A Transformação Produtiva seria obtida com a maior abertura externa, que incentivaria o progresso técnico interno pela força da concorrência, enquanto a eqüidade seria atingida com uma combinação dos efeitos de longo prazo das reformas, associados às políticas sociais compensatórias.

A aceitação da idéia ortodoxa segundo a qual as reformas neoliberais pró-mercado são a única forma possível para o desenvolvimento das economias emergentes, tendo o Estado apenas o papel de regular os mercados, para que estes possam dar a definição dos setores prioritários e das trajetórias do desenvolvimento, é o que nos permite entender o pensamento da Nova CEPAL como um reformismo conservador. Isso é explícito em um de seus defensores:

O programa de investigação cepalina nos anos 1990 volta seu foco às transformações provocadas por outra mudança de modelo de acumulação na região, ou seja, a que se dá pela reorientação dos marcos regulatórios, por intermédio da liberalização dos mercados e pela reforma do Estado, especialmente via privatizações. Este programa parte do reconhecimento de que este conjunto de reformas liberalizantes pode ter influência positiva sobre o processo de crescimento, desde que seja bem conduzido (BIELSCHOWSKY, 2000, p. 68).

\subsection{Perspectiva da Nova CEPAL sobre o Sistema Financeiro Internacional}

José Antonio Ocampo, secretário executivo da CEPAL nos anos 90, conseguiu resumir a perspectiva da Nova CEPAL a respeito do novo contexto internacional que teria obrigado a agência a reformular seu pensamento. Para ele, existiriam consensos e discordâncias no debate econômico sobre a globalização financeira e o sistema financeiro internacional. Um dos principais consensos “...es el amplio reconocimiento actual de que la liberalización de la cuenta de capitales debe ser ordenada y cautelosa, especialmente en lo que se refiere a los flujos de corto plazo, que debe tener como prerrequisito el desarrollo de fuertes mecanismos de regulación y supervisión prudencial a nivel nacional..." (OCAMPO, 1999, p. 11).

As discordâncias estariam restritas a cinco esferas:

a) financiamento dos mecanismos de contingência (formas e instrumentos de financiamento);

b) uso dos direitos especiais de saque junto ao FMI em momentos de crise;

c) condições impostas pelo FMI dentro de pacotes de ajuda;

d) manutenção da autonomia na administração da conta de 
capital, enquanto não exista um ordenamento adequado do sistema financeiro internacional;

e) estabelecimento de instituições financeiras de caráter regional e subregional.

Independente de qual seja o posicionamento da Nova CEPAL a respeito dos pontos onde existe discórdia, o que queremos ressaltar é a compreensão do neoestruturalismo sobre o que seria consenso. Não haveria nenhuma discordância de que a conta de capital deve ser liberalizada, aprofundando o grau de abertura financeira das economias periféricas, ainda que de forma ordenada e cautelosa. Essa cautela seria justificada pela volatilidade dos fluxos de capital de curto prazo, volatilidade esta que deveria ser controlada por mecanismos de regulação e supervisão preventiva, exatamente como na proposta novo-keynesiana a la Stiglitz. A entrada de capital externo teria, portanto, um papel positivo, desde que se dirigisse para o financiamento do investimento produtivo.

Sinteticamente, não se trataria de reduzir o grau de liberalização financeira externa, embora eles reconheçam que o capital externo gera instabilidade nas taxas de câmbio, no grau de controle da oferta de crédito e da demanda agregada, no preço dos ativos, nos passivos externos e na vulnerabilidade futura a novos choques externos (CEPAL, 1998). Mas trata-se de utilizar a política regulatória, até de controles de capital quando necessário, ${ }^{14}$ no sentido de incentivar os investimentos produtivos com capitais externos de longo prazo, e desincentivar a entrada de capitais de curto prazo com interesses meramente especulativos.

\subsection{Papel da abertura externa: ciclo do endividamento virtuoso e abertura comercial}

É justamente aqui que a Nova CEPAL defende uma das principais reformas neoliberais implementadas na América Latina, a abertura externa, tanto financeira como comercial.

Esta argumentação se assenta na idéia do ciclo de endividamento virtuoso (CEPAL, 1998), segundo a qual existiriam três fases

${ }^{14}$ A política regulatória que utilize controles de capital, no sentido de selecionar o capital externo, deveria controlar a entrada de capital, e não a saída, fazendo uma seleção qualitativa por meio da implementação de uma quarentena e/ou uma taxação decrescente conforme o prazo de permanência do capital. Não é proposto de forma alguma o controle quantitativo do capital externo. O importante é que estes controles de capital não significam uma restrição à abertura externa, em primeiro lugar porque seriam transitórios, e em segundo lugar porque teriam um caráter meramente seletivo. 
para que o financiamento externo do crescimento gerasse as divisas necessárias para saldar os compromissos assumidos inicialmente. $\mathrm{Na}$ primeira fase, em que a taxa de investimento do país é maior do que a poupança interna disponível, o "gap" existente é financiado pelo capital externo. Nesse período inicial, a dívida externa cresce mais rápido do que o $\mathrm{PIB}$, porque os novos empréstimos são tomados para sustentar o déficit de poupança interna e o refinanciamento da dívida que por ventura for vencendo. No período seguinte, o crescimento econômico conseguido com o financiamento externo produz um excesso de poupança interna com respeito aos níveis de investimento, o que lhe permitirá pagar progressivamente os juros da dívida contraída. O saldo comercial, por sua vez, passa a ser positivo nesta segunda fase, ao contrário da primeira. ${ }^{15}$ Isso possibilita que a taxa de crescimento da dívida decline gradualmente até se tornar inferior à taxa de crescimento do PIB e o estoque de dívida pare de crescer. Na última fase, o crescimento econômico e a expansão do excedente de poupança interna permitem que o país pague os juros da dívida e comece a amortizar o principal da mesma, até que ela se anule.

O gráfico 1 mostra essas três fases do ciclo do endividamento virtuoso. A passagem da fase I para a fase II ocorre justamente quando o hiato de poupança $\mathrm{N}(\mathrm{t})$ passa a ser negativo, ou seja, quando a poupança interna, gerada pelo crescimento econômico que foi financiado externamente, começa a superar o investimento. Portanto, é a partir desse ponto que a balança comercial se reverte; de negativa ela passa a ser positiva. Em razão disso, como visto, nessa segunda fase a taxa de crescimento do estoque do endividamento externo começa a declinar. A passagem da fase II para a fase III se dá no ponto de maior valor do estoque de endividamento externo. A partir dessa terceira fase, o valor desse estoque passa a cair até o momento em que ele se anula.

Esta idéia que embasa o pensamento cepalino só se sustenta se forem observadas cinco premissas. Inicialmente, a entrada de capital externo não pode financiar o consumo interno, mas deve dirigir-se para investimentos produtivos que permitam o crescimento econômico posterior. Em segundo lugar, e relacionado com o anterior, o capital externo não pode ser de curto prazo com interesses meramente especulativos para aproveitar-se de ganhos de arbitragem, mas deve

15 Com déficit orçamentário nulo, a identidade básica macroeconômica garante que um excesso de investimento sobre poupança interna se traduza em déficits comerciais, no primeiro caso, e vice-versa no segundo. 


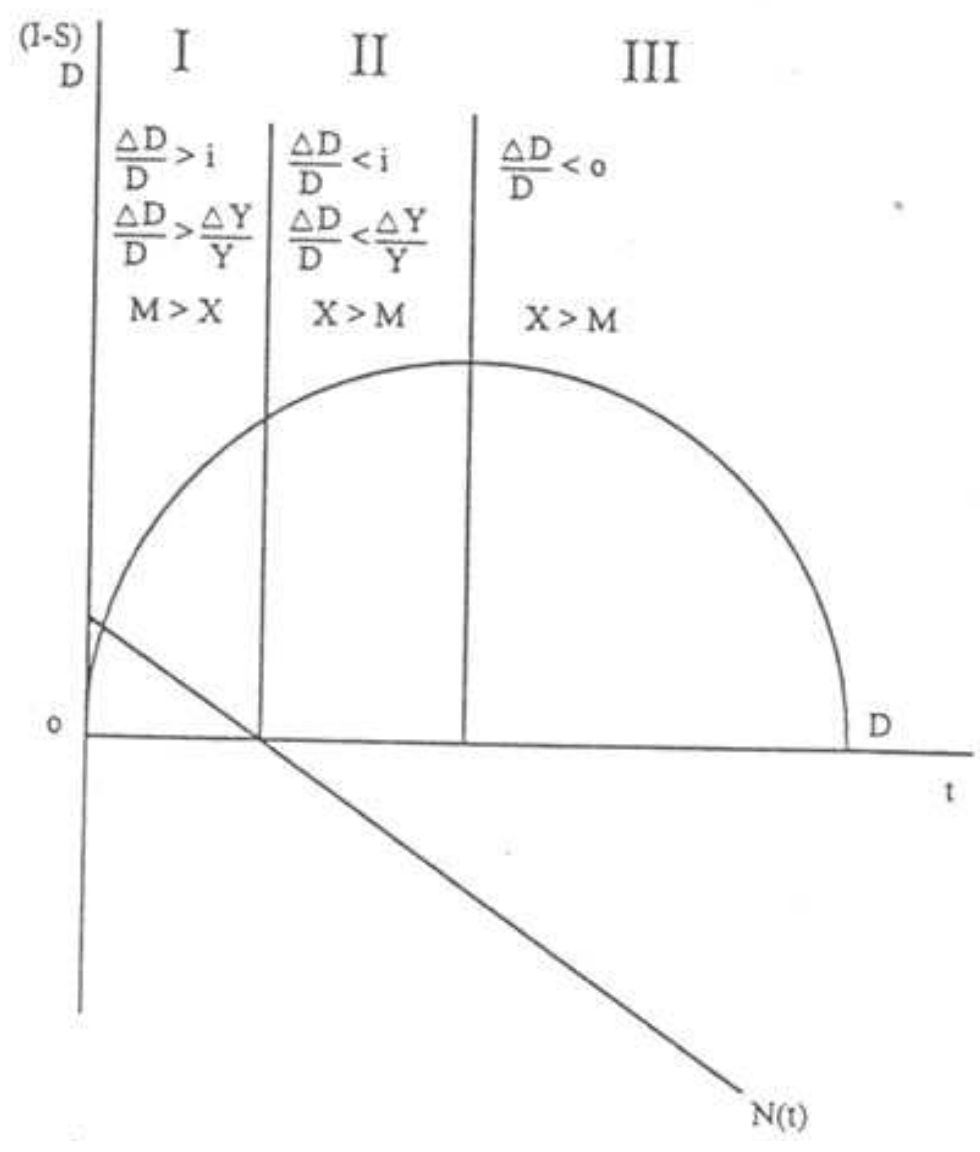

Gráfico 1. Fases do financiamento externo e hiato de poupança

ser direcionado para aplicações de longo prazo. Por último, o acréscimo de investimento produtivo deve se traduzir em expansão de produção de bens transacionáveis no mercado externo, pois é a geração de saldos comerciais positivos que garantirá o pagamento do endividamento externo. Neste momento, é que aparece o papel da política comercial. Não se trata, como visto, de recuar nas reformas comerciais neoliberais, mas de tomá-las como ponto de partida. As políticas comerciais seletivas, segundo a agenda cepalina, estariam orientadas a superar as insuficiências dos mercados e a aproveitar as externalidades, de forma a garantir que o acréscimo de capacidade produtiva fosse voltado para a promoção das exportações (CEPAL, 1998). 
Estas três premissas para que "funcione" o ciclo do endividamento virtuoso são reconhecidas pela Nova CEPAL, mas existem outras duas. Para que a economia em questão consiga gerar os recursos (poupança interna e saldos comerciais) com capacidade para pagar o endividamento contraído, que possibilita o financiamento do investimento e do crescimento, é necessário que a taxa de correção dessa dívida seja estável ou, no mínimo, que não seja muito volátil. Se as taxas de juros internacionais que corrigem o endividamento crescerem, o pagamento de juros crescerá, a economia necessitará refinanciar os seus débitos e, portanto, o endividamento crescerá. No gráfico 1, isso implicará em que o ponto de máximo da curva da dívida (na separação entre as fases II e III) se deslocaria para a direita, assim como o pagamento total do endividamento, no momento em que a dívida fosse zerada. No limite, esse crescimento da dívida em razão do aumento das taxas de juros poderia inviabilizar o pagamento da dívida, em razão da insuficiente criação de recursos internos para pagar um endividamento crescente, transformando um problema de liquidez em problema de insolvência. ${ }^{16}$

Há ainda uma outra premissa, não reconhecida pela Nova CEPAL, para que funcione o ciclo do endividamento virtuoso. Se o financiamento externo ocorrer com uma boa parcela de investimento direto estrangeiro, é preciso que exista um controle sobre a remessa futura de lucros e dividendos. A entrada de capital produtivo externo pode aumentar a produção interna de riqueza, se observadas as premissas anteriores, mas a sua apropriação/acumulação não tem garantia de ocorrer internamente. A tendência do capital externo, ao se apropriar dos lucros e dividendos, é remete-los em grande parte para suas matrizes ou para investimentos em outras localidades. Isso provoca uma saída de recursos pela balança de serviços, pressionando negativamente as transações correntes e aumentando a necessidade de financiamento externo. O endividamento pode se tornar explosivo e provocar as mesmas conseqüências da elevação das taxas de juros internacionais.

Obviamente, a Nova CEPAL não deve desconhecer essas premissas adicionais para que tenha validade o seu modelo para o capital externo. Entretanto, reconhecer a necessidade de algum controle sobre a remessa de lucros e dividendos significa reconhecer a necessidade de restringir o grau de liberalização do capital externo,

${ }_{16}$ Adaptando a linguagem de Minsky para um caso de uma economia em suas relações com o exterior, é como se essa estrutura de financiamento se transformasse de hedge em especulativa ou Ponzi, acentuando a fragilidade financeira e potencializando a possibilidade de ocorrência de uma crise. De virtuoso, o ciclo de endividamento se tornaria vicioso. 
o que se choca com a premissa neoestruturalista de não questionar as reformas neoliberais.

Ainda assim, a principal pista para constatar o caráter ortodoxo da Nova CEPAL está na premissa teórica que sustenta o modelo de endividamento virtuoso: o hiato de poupança interna. Existiria a necessidade de atrair capital externo única e exclusivamente porque a poupança interna seria insuficiente para financiar os investimentos necessários para retomar o crescimento. Tomando a identidade macroeconômica básica, e desconsiderando a poupança do governo, o maior investimento interno sobre a poupança implicaria saldos comerciais negativos, que devem ser financiados com entrada de capital, isto é, com poupança externa. A premissa teórica que está por trás deste raciocínio é que um fluxo maior de investimentos só é possível se existir poupança acumulada previamente, ainda que seja poupança externa. Ora, a determinação do investimento por uma poupança prévia é justamente a hipótese básica de qualquer modelo ou teoria ortodoxa.

Como já se viu, a abertura comercial também tem o seu papel dentro desta perspectiva. A transformação produtiva deveria acontecer por um aumento de competitividade não oriundo de reduções de salário real. Assim, além do fato da reversão da política de abertura comercial possuir um custo muito alto, sendo conveniente mantê-la, o seu aprofundamento seria defensável como forma de estímulo à incorporação de progresso técnico e elevação da produtividade. Segundo Bielschowsky (2000, p. 65), "propõe-se uma maior abertura da economia, gradual e seletiva, como meio de introduzir o progresso técnico e o aumento da produtividade". Como visto, o caráter seletivo da política comercial não procura recuar na reforma, mas superar eventuais falhas de mercado.

A defesa das reformas neoliberais, em específico dos processos de abertura comercial e financeira é que coloca a Nova CEPAL dentro do pensamento ortodoxo contemporâneo. Que seja proposta uma Reforma das reformas, no sentido de torna-las graduais e seletivas em nada modifica a situação, como veremos a seguir.

\section{A Estratégia Neoliberal de Desenvolvimento do Consenso de Washington}

Ao contrário do que se costuma supor, o ajuste neoliberal e, em específico, as políticas propostas pelo Consenso de Washington, não se resumem à estabilização macroeconômica, mas conformam 
uma concepção de desenvolvimento da qual a primeira é apenas um componente. ${ }^{17}$ Pode-se dividir o programa de ajuste neoliberal em três elementos, ou componentes distintos. ${ }^{18}$

O primeiro componente seria o da estabilização macroeconômica, com o objetivo de reduzir a inflação e controlar as contas governamentais. Não se pode dizer que haja uma política econômica de estabilização claramente neoliberal, apenas que o fracasso das políticas ortodoxas para completar este elemento do programa neoliberal provocou a introdução de instrumentos heterodoxos no combate à inflação, como a utilização da âncora cambial, seja na forma de regimes dolarizados ou de bandas cambiais. ${ }^{19}$

As reformas estruturais de abertura comercial, desregulamentação dos mercados, privatização de estatais e de serviços públicos, a eliminação da maior parte dos subsídios, garantindo a liberalização dos preços, e a abertura financeira, formam o segundo elemento. São pré-condições estruturais que possibilitam o funcionamento da economia de mercado, com prudência fiscal, apoiada na iniciativa privada que, para o pensamento neoliberal, garantem o terceiro elemento do programa com a retomada dos investimentos e crescimento econômico associado à distribuição de renda para os países periféricos. ${ }^{20} \mathrm{~A}$ economia de mercado, funcionando sem intervenções e/ou regulamentações levaria à ordem natural harmônica, ao desenvolvimento econômico.

${ }^{17}$ Este enfoque [neoliberal] tem se refletido em algumas reformas fundamentais das políticas e dos mercados, e tem um duplo objetivo de estabilização macroeconômica e desenvolvimento da competitividade internacional" (ROSENTHAL, 1996, p. 11). Este último aspecto é que propiciaria o crescimento de mais longo prazo, como reconhece este importante autor do novo pensamento Cepalino.

${ }^{18}$ Na realidade, Fiori (1997, p. 12) define o programa neoliberal em três fases. O termo "fase", empregado por ele, talvez não seja o melhor, pois pode dar a idéia de uma seqüência necessária e mecânica, sem interfaces. Cano (1999, p. 300) prefere falar em dois principais conjuntos que compõem as reformas neoliberais. Esses dois conjuntos correspondem às duas primeiras fases definidas por Fiori: estabilização e reformas estruturais. Indo mais além da mera análise da concepção/implementação do programa neoliberal, Cano (2000) faz um exaustivo apanhado dos resultados promovidos por essas experiências na América Latina, demonstrando o fracasso das políticas neoliberais em função de suas próprias promessas de desenvolvimento.

19 Portanto, não é possível qualquer tipo de identificação do ajuste neoliberal apenas com políticas ortodoxas de administração de demanda, ainda que estas tenham sido aplicadas em algum momento.

${ }^{20}$ É neste ponto que se define o maior perigo de entender o termo "fase" como algo necessariamente seqüencial. Assim procedendo, acaba-se por aceitar o argumento neoliberal de que o desenvolvimento (fase III) é fruto necessário das reformas neoliberais (fase II). Embora isto não passe de um wishful thinking, é exatamente assim que o argumento costuma ser apresentado pelos seus simpatizantes. 
Evidentemente, a seqüência aqui ilustrada de implementação deste programa não é tão mecânica. Há instrumentos da fase de reformas estruturais, por exemplo, que ajudam na estabilização macroeconômica, ou seja, podem existir situações concretas em que instrumentos das duas primeiras fases podem se sobrepor. A abertura comercial, elemento das reformas estruturais, promove a concorrência entre os produtos importados e os nacionais, o que tende a reduzir os preços domésticos. A desregulamentação (flexibilização) do mercado de trabalho, por sua vez, pode reduzir os custos do trabalho, segundo o discurso neoliberal, na medida em que diminui os encargos sobre o trabalho, proporcionando o aumento do número de vagas no mercado de trabalho e contribuindo também para o combate à inflação.

Essa característica leva alguns autores a argumentar que não é possível chamar o enfoque neoliberal de paradigma por causa de suas diferentes aplicações práticas em termos de instrumentos, ritmo de implementação, seqüência e combinação de políticas, em função das diversas especificidades dos países que implementaram esse tipo de enfoque. Rosenthal (1996) cita os distintos regimes cambiais adotados, as diferentes políticas de estabilização macroeconômica e a forma diferenciada como foi liberalizada a conta de capital, como exemplos deste tipo de argumento.

Entretanto, a diversidade de formas de implementação da estabilização e da abertura externa não é o que define o programa neoliberal, mas a natureza das reformas. Em primeiro lugar, é importante a estabilização macroeconômica, independentemente da forma (ortodoxa ou heterodoxa) utilizada, pois ela é considerada uma pré-condição para os outros dois componentes do programa. ${ }^{21}$ Entretanto, a principal diretriz do programa neoliberal, dada a estabilização, são as reformas estruturais que, supostamente, garantiriam o crescimento e o desenvolvimento futuros, pois elas gerariam a concorrência entre a iniciativa privada, levando a ganhos de produtividade e competitividade. Em suma, a política neoliberal se define por um ideário de mais longo prazo, uma concepção de desenvolvimento, embora tenha como pré-condição uma política de estabilização de curto prazo, ortodoxa ou não. ${ }^{22}$

${ }^{21}$ A estabilização é um dos principais componentes para a obtenção dos chamados fundamentos que, após a abertura externa, garantem a absorção de capitais externos.

22 Nesse sentido, o Plano Real faz parte de um programa neoliberal de desenvolvimento “...por sua concepção estratégica de longo prazo, anunciada por seus autores, desde a primeira hora, como condição inseparável de seu sucesso no curto prazo (...) para que só depois de restaurada numa economia aberta de mercado possa dar-se então a retomada do... 


\subsection{A revisão do pensamento ortodoxo para justificar a abertura externa}

Dentre as reformas estruturais, a abertura externa é uma das mais importantes, até como forma de obter o financiamento externo e incentivar a concorrência e a produtividade, fatores tidos como necessários para a retomada do crescimento. Essa abertura externa é composta pela abertura comercial, no que se refere à liberalização das importações e à promoção das exportações, pela abertura na conta de transações correntes, traduzida na maior facilidade de remessa de lucros e dividendos, por exemplo, e pela liberalização da conta de capital. Do lado financeiro, um maior grau de abertura significa uma maior facilidade dos residentes para adquirir direitos e assumir obrigações em moeda estrangeira e dos não-residentes em acessar os vários setores do mercado financeiro local (AKYÜZ, 1992).

Especificamente no que se refere à abertura externa, o pensamento neoliberal passou de uma defesa do tratamento de choque, para um argumento seqüencial. ${ }^{23} \mathrm{O}$ tratamento de choque ou liberalização radical não se preocupava com alguma seqüência na liberalização comercial e da conta de capital, limitando-se a apregoar as benesses das duas.

Após a primeira fase em que o argumento ortodoxo da liberalização radical e do tratamento de choque não foram respaldados pelas experiências latino-americanas da década de 70 , a explicação convencional passou para um segundo momento em que se defendeu o argumento seqüencial (MCKINNON, 1991). Segundo ele, a simultaneidade do processo de abertura poderia levar a um superendividamento externo e à valorização cambial, uma vez que, com a desrepressão financeira, as taxas de juros domésticas seriam superiores às internacionais, provocando uma forte e súbita entrada de capitais. Isso traria o superendividamento externo (overborrowing syndrome) e a valorização cambial. Esta última, em conjunto com a abertura comercial, levaria a fortes saldos negativos na balança comercial, o que poderia comprometer as contas externas do país em questão. Além disso, a simultaneidade do processo de abertura poderia levar ao financiamento da importação de bens de consumo, o que implicaria na redução da importação de bens de investimento e na diminuição do investimento nos setores produtores de bens exportáveis.

crescimento" (FIORI, 1997, p. 14). Para o mesmo aspecto, só que para o caso chileno da década de 70, ver Foxley (1988).

23 Mckinnon (1973) e Mckinnon (1991). 
É por isso que a abertura externa deve-se dar de forma seqüencial. A seqüência ótima proposta por Mckinnon (1991, p. 4-10) deveria ser iniciada por uma reforma fiscal que reduzisse a rigidez nas taxas de juros, ou seja, reduzisse a necessidade de rolagem da dívida pública com custos cada vez maiores. A idéia desta primeira etapa é a de que, com uma reforma fiscal conseqüente, o Estado reduzisse os seus déficits e, com isso, a necessidade de financiá-los com novo endividamento público. Isto, ao mesmo tempo em que reduziria o déficit público, influiria positivamente nas expectativas dos agentes quanto à capacidade do setor público em honrar seus compromissos, o que reduziria as taxas de juros pagas sobre novos títulos públicos lançados no mercado.

A segunda etapa seria a desregulamentação financeira doméstica (liberalização financeira interna), através da eliminação de recursos e créditos dirigidos e dos créditos preferenciais, da redução das reservas compulsórias impostas aos bancos, da redução/eliminação de outras restrições bancárias, como a obrigatoriedade de compra de títulos públicos e requisitos mínimos para crédito, e da desregulamentação dos tipos e estruturas de passivos. Além disso, a liberalização financeira interna requereria a privatização dos bancos estatais e das instituições de seguro. O objetivo central da liberalização financeira interna seria dar exclusividade ao mercado na alocação dos recursos financeiros e na determinação da taxa de juros. Estas duas primeiras etapas completariam a desrepressão financeira interna. ${ }^{24} \mathrm{~A}$ principal vantagem da desrepressão financeira interna, segundo esta perspectiva, é dada pelo fato de que ela permitiria sanar o determinante do atraso econômico dos países periféricos: escassez crônica de poupança interna. A repressão financeira significaria o controle e/ou determinação da taxa de juros por mecanismos extra-mercado, mantendo essa taxa em patamares artificialmente baixos, reprimindo a poupança e a oferta de crédito. Completada a desrepressão, o acréscimo de poupança financiaria o investimento em expansão.

Dando início a abertura externa, a terceira etapa teria que ser a unificação do mercado cambial, antes da liberalização externa, para acabar com as discriminações contra exportadores e/ou importadores potenciais. A quarta etapa é a da abertura comercial que, segundo Krueger (1978) e Bhagwati (1978), também deveria ser feita em seqüência. Inicialmente, seriam eliminadas gradualmente as quotas de importação, ao mesmo tempo em que se promove uma desvalorização da taxa de câmbio que se traduza em desvalorização

${ }^{24}$ Uma excelente análise crítica dessa perspectiva se encontra em Cintra (1999). 
da taxa de câmbio real, a fim de reduzir o viés anti-exportador das economias fechadas e prevenir a ocorrência de déficits na balança comercial. Em seguida, as quotas seriam convertidas em tarifas, de forma a acabar com as barreiras não-tarifárias. Por último, estabelecer-se-ia a plena conversibilidade em conta corrente, seriam reduzidas as tarifas médias de proteção e não seriam mais utilizadas quotas como forma de atenuar desequilíbrios no balanço de pagamentos.

Completada a abertura comercial, seria implementada a quinta e última etapa da seqüência ótima de abertura externa, a liberalização financeira externa que, como definido anteriormente, deveria significar o aumento do grau de abertura financeira, isto é, a maior facilidade com que os residentes de um país podem adquirir ativos e passivos expressos em moeda estrangeira e os não-residentes podem operar nos mercados financeiros nacionais.

Todas essas reformas deveriam, evidentemente, ser precedidas de uma estabilização macroeconômica que garantisse a credibilidade para a implementação das primeiras. A implementação dessa seqüência ótima de reformas liberais garantiria o cumprimento de uma disciplina econômica (obtenção dos tais fundamentals), que sustentariam a continuidade de entrada de capital externo que financiaria o desenvolvimento econômico.

As crises financeiras e cambiais da década de 90 obrigaram o pensamento ortodoxo a reformular-se mais uma vez. Na sua constante luta contra as evidências empíricas em busca de se adequar ex-post aos fatos, o pensamento convencional entrou em uma terceira fase reconhecendo que a seqüência das reformas é importante, porém é insuficiente, e pode levar a instabilidades financeiras e crises cambiais. ${ }^{25}$

Como as críticas à liberalização financeira costumam se assentar na ineficiência dos mercados, esta terceira fase do pensamento ortodoxo tende a complementar o argumento seqüencial com medidas que minimizam essas imperfeições de mercado.

No que se refere aos mercados financeiros, sua ineficiência estaria dada muito mais pela existência de informações assimétricas do que pela liberalização em si. A fragilidade financeira, característica das economias que enfrentaram crises financeiras e/ou cambiais, teria origem no caráter incompleto das informações relevantes para que os agentes tomem suas decisões nos mercados financeiros, e não em algo intrínseco à própria natureza destes mercados. A

25 Estes argumentos podem ser encontrados em Eichengreen et al. (1998), Eichengreen et al. (1999), Demirgüç-Kunt e Detragiache (1998), Stiglitz (1999) e Hausmann e Rojas-Suárez (1996). 
existência de informações assimétricas, em um processo de abertura financeira, geraria alguns problemas para a eficiência desses mercados: (i) racionamento de crédito, uma vez que os credores não possuiriam todas as informações necessárias sobre os tomadores de empréstimos (DEVLIN et al., 1997); (ii) seleção adversa, segundo o qual os investimentos com menores chances de sucesso "expulsariam" do mercado aqueles com maiores chances, justamente pela impossibilidade dos credores hierarquizarem perfeitamente os planos de investimento segundo suas diferentes viabilidades (EICHENGREEN et al., 1998 e 1999); (iii) risco moral, em que a existência de emprestadores de última instância com atuação não seletiva faz com que os agentes em dificuldades sintam segurança em tomar empréstimos para investir em operações cada vez mais arriscadas (DEMIRGÜÇ-KUNT E DETRAGIACHE, 1998); e (iv) comportamentos de manada, onde os agentes sem informação privilegiada procurariam seguir aqueles que pretensamente a possuíssem, o que poderia redundar em tendências auto-referendadas.

Dessa forma, embora a seqüência na abertura externa seja uma medida importante, as imperfeições relativas às informações assimétricas nos mercados financeiros exigiriam uma intervenção estatal corretiva, composta por uma supervisão das instituições financeiras, uma regulação preventiva e por um comportamento mais cuidadoso e seletivo do emprestador de última instância. ${ }^{26}$ Apesar de se requerer essa intervenção, é evidente que ela só se define como uma forma complementar às determinações do mercado financeiro, ou melhor, é apenas um meio de fornecer um ambiente econômico mais estável para que os agentes possam fazer uso das informações disponíveis da melhor forma possível. Não se trata em nenhuma hipótese de restringir a liberalização financeira, mas apenas de complementá-la com um aparato regulatório. As benesses do funcionamento dos mercados continuam sendo apregoadas. Isto é claro quando Stiglitz (1999, p. 106) afirma que "a estabilidade macroeconômica e o desenvolvimento de longo prazo requerem mercados financeiros sólidos. Mas, a agenda para gerá-los não pode confundir meios com fins; o redesenho do sistema regulatório, e não da liberalização financeira, deve ser o instrumento".

Este é o atual "estado das artes" da argumentação a favor da liberalização financeira externa. Resta saber quando a realidade do comportamento dos mercados financeiros obrigará a concepção

26 "Com estas salvaguardas, a liberalização se torna não apenas inevitável, mas claramente benéfica” (EICHENGREEN et al., 1999, p. 10). 
ortodoxa a uma nova revisão (reforma) dos seus argumentos. Até lá, a intervenção estatal, apenas no sentido regulatório, ainda é importante, já que os benefícios da abertura seqüencial parecem demorar a acontecer. ${ }^{27}$

O caráter ineficiente, ou incompleto, dos mercados também é o que orienta o revisionismo presente nos novos modelos do comércio internacional. É justamente porque as hipóteses do modelo tradicional Heckscher-Ohlin-Samuelson (H-O-S) de retornos constantes de escala, que leva ao equilíbrio competitivo, e de existência de equilíbrio com concorrência perfeita não se verificam no realconcreto, que surgem situações em que se vislumbram formas de proteção comercial. Como os mercados costumam operar com retornos crescentes e concorrência imperfeita, a política comercial ativa possui um papel importante em duas frentes (KRUGMAN, 1988):

(I) ela pode ser utilizada para reduzir o poder de mercado das empresas estrangeiras no mercado interno, tanto no que se refere às importações como ao investimento direto;

(II) ela pode reforçar o poder de mercado das empresas nacionais em sua competição no estrangeiro.

Ainda que esses "novos" teóricos do comércio internacional sejam menos dogmáticos a respeito dos custos do protecionismo, eles aceitam muitos dos postulados de seus predecessores (TAYLOR, 1988 , p. 84). Os primeiros não rebatem o argumento da vantagem comparativa como fonte de especialização. Ao contrário, eles a complementam, de forma que o padrão de comércio continua sendo determinado pelas preferências, tecnologias e recursos dos países, mas também por razões como as economias de escala.

Isto faz com que a melhor política para as imperfeições de mercado diagnosticáveis seja a atuação direta sobre elas, de forma a corrigir as falhas de mercado. As políticas comerciais só se justificam em situações em que essas falhas tenham sua origem no contexto internacional e, portanto, não sejam passíveis de tratamento mediante uma política nacional. Desta feita, "não há nada até agora na nova teoria que possa restabelecer a respeitabilidade intelectual da estratégia de substituição de importações. A industrialização com substituição de importações é vista de forma ainda pior na nova teoria do que na teoria tradicional" (KRUGMAN, 1988, p. 58). Por essas palavras daquele que talvez seja o maior propagandista desta "nova" teoria, pode-se concluir que a proteção comercial não só é

${ }^{27}$ Por mais incrível que possa parecer, é exatamente isto que Fanelli e Frenkel (1994) argumentam. Segundo eles, os benefícios da abertura podem levar até uma década! Em outras palavras, não resta mais nada a fazer (além da presença regulatória do Estado) a não ser esperar. 
rejeitada enquanto estratégia de desenvolvimento, como ainda o é em grau mais elevado do que antes. A abertura comercial continua sendo a meta, embora eventuais imperfeições de mercado dêem espaço a políticas comerciais ativas, mas de caráter corretivo e até transitório.

Esta perspectiva revisionista de correção das imperfeições de mercado também pode ser encontrada nos trabalhos recentes da CEPAL, dentro da idéia de Reforma das reformas. Segundo essa perspectiva, os países periféricos, em especial os da América Latina e Caribe, não deveriam retroceder nas reformas neoliberais, nem muito menos rechaçá-las. Muito pelo contrário, esses países deveriam tomar as reformas como um dado e, a partir delas, buscar os elementos de política que conseguissem aumentar o grau de eqüidade social. $^{28}$

Do ponto de vista geral da estratégia de desenvolvimento, um dos principais autores da Nova CEPAL acaba concluindo o mesmo: "por certo, os princípios que inspiram esta virada [neoliberal] - a economia de mercado, a propriedade privada, a prudência fiscal e o protagonismo do setor privado - são patrimônio das principais correntes do pensamento econômico atual: do neoliberalismo por um lado e do neoestruturalismo por outro" (RAMOS, 1997, p. 16). A diferença que existiria entre as duas correntes, segundo o próprio autor, é que os neoestruturalistas (neocepalinos) acreditariam que esses princípios são condição necessária para o desenvolvimento, mas não suficiente. Restaria ao Estado corrigir as falhas do mercado, especificamente, implementar medidas adicionais para evitar problemas distributivos, já que as reformas neoliberais trazem resultados apenas no longo prazo. Se este autor tiver razão, o projeto Reforming the reforms ${ }^{29}$ da nova CEPAL não parece estar muito longe do revisionismo do pós-Consenso de Washington, como define Stiglitz (1999): o Estado como suporte da natureza e lógica dos mercados.

Em suma, a nova proposta cepalina não é de reversão das reformas, mas de gerenciamento e direcionamento dos efeitos da abertura comercial e da liberalização financeira externa, de forma a canalizar o capital externo para atividades produtivas voltadas preferencialmente para as exportações, ao mesmo tempo em que se procura a eqüidade social, embora as políticas para tanto sejam muito mais de caráter compensatório, do que de reversão de estratégia

${ }^{28}$ Na Nova CEPAL, o reformismo pelo lado macroeconômico converge com o reformismo pelo lado social expresso pela visão da "Transformación Productiva con Equidad".

${ }^{29}$ No que se refere aos impactos da abertura externa, o projeto de reforma das reformas pode ser encontrado em Ffrench-Davis (1999) e Ocampo (1999). 
de desenvolvimento propriamente dita. ${ }^{30} \mathrm{~A}$ agenda cepalina de reforma das reformas parece significar muito mais um gerenciamento das "imperfeições" das reformas neoliberais do que uma concepção significativamente distinta de desenvolvimento. No passado, a CEPAL caminhava em sentido contrário do pensamento liberal-conservador-ortodoxo. Atualmente, a CEPAL acompanha o pensamento convencional, isso quando não vai a reboque do revisionismo, com seu modelo de Reforma das reformas.

\section{Abertura e Vulnerabilidade Externa}

Se a proposta da Nova CEPAL se enquadra dentro do pensamento neoliberal do Consenso de Washington e, portanto, não pode ser alternativa, como construí-la?

As reformas neoliberais na América Latina aprofundaram os problemas estruturais de suas economias. A tabela 1 mostra as taxas de crescimento das principais economias latino-americanas ao longo do período entre 1971 e 2004. Considerando o período mais intenso das reformas neoliberais como sendo entre 1990-2004, percebe-se que a taxa de crescimento média no período (2,6\%) é muito inferior à observada entre 1971-1980 (5,6\%). O resultado do período neoliberal, amplamente apoiado na abertura externa só não foi pior do que o obtido entre 1981-1989 (1,3\%), justamente a década perdida.

Tabela 1. Taxas de crescimento do PIB da América Latina, 1971-2004 (\%)

\begin{tabular}{|l|l|l|l|l|l|l|}
\hline & $\mathbf{1 9 7 1 - 8 0}$ & $\mathbf{1 9 8 1 - 8 9}$ & $\mathbf{1 9 9 0 - 9 7}$ & $\mathbf{1 9 9 8 - 0 3}$ & $\mathbf{2 0 0 4}$ & $\mathbf{1 9 9 0 - 0 4}$ \\
\hline Argentina & 2,8 & $-1,0$ & 5,0 & $-1,4$ & 9,0 & 2,6 \\
\hline Brasil & 8,6 & 2,3 & 2,0 & 1,2 & 5,2 & 2,0 \\
\hline Chile & 2,5 & 2,8 & 7, & 2,7 & 6,0 & 5,2 \\
\hline Colômbia & 5,4 & 3,7 & 3,9 & 1,0 & 3,5 & 2,8 \\
\hline México & 6,5 & 1,4 & 3,1 & 2,8 & 4,4 & 3,1 \\
\hline Peru & 3,9 & $-0,7$ & 3,9 & 2,0 & 5,1 & 3,2 \\
\hline Uruguai & 2,7 & 0,4 & 3,9 & $-2,5$ & 11,8 & 1,8 \\
\hline Venezuela & 1,8 & $-0,3$ & 3,8 & $-2,8$ & 17,3 & 1,9 \\
\hline América Latina & & & & & & \\
\hline - Total & $\mathbf{5 , 6}$ & $\mathbf{1 , 3}$ & $\mathbf{3 , 2}$ & $\mathbf{1 , 2}$ & $\mathbf{5 , 8}$ & $\mathbf{2 , 6}$ \\
\hline - Por habitante & $\mathbf{3 , 0}$ & $\mathbf{- 0 , 8}$ & $\mathbf{1 , 4}$ & $\mathbf{- 0 , 4}$ & $\mathbf{4 , 2}$ & $\mathbf{0 , 9}$ \\
\hline - Por trabalhador & $\mathbf{1 , 7}$ & $\mathbf{- 1 , 5}$ & $\mathbf{0 , 5}$ & $\mathbf{- 1 , 2}$ & $\mathbf{3 , 4}$ & $\mathbf{0 , 0}$ \\
\hline
\end{tabular}

Fonte: Ffrench-Davis (2005, p.20)

${ }^{30}$ Como se a desigualdade social e a concentração de renda já não fossem algo inerente ao modelo 
Deve-se ressaltar que o desempenho ainda foi pior entre 19982003 (1,2\%), em razão das diversas crises cambiais e de balanço de pagamentos em várias economias da região, em razão da vulnerabilidade externa gerada pelas estratégias neoliberais. Observando o crescimento do PIB per capita entre 1990-2004 evidencia-se a mediocridade do desempenho (0,9\%). Se observado o crescimento do PIB por trabalhador, um indicador de produtividade, o resultado é inegável: a produtividade da região no período ficou estagnada.

Contrariando todas as promessas do discurso político-ideológico, o desempenho da economia da América Latina em seu período neoliberal é um fiasco.

Tabela 2. Indicadores sociais da América Latina, 1980-2004

\begin{tabular}{|l|l|l|l|l|}
\hline Ano & $\begin{array}{l}\text { PIB per capita } \\
\text { (US\$ de 1995) }\end{array}$ & $\begin{array}{l}\text { Pobreza } \\
\text { (\% da população) }\end{array}$ & $\begin{array}{l}\text { Salário real médio } \\
(1995=100)\end{array}$ & $\begin{array}{l}\text { Taxa de desemprego } \\
\text { (\% da força de trabalho) }\end{array}$ \\
\hline 1980 & 3.687 & 40,5 & 102,7 & 7,7 \\
\hline 1990 & 3.345 & 48,3 & 96,2 & 7,3 \\
\hline 2004 & 3.913 & 42,9 & 96,8 & 10,0 \\
\hline
\end{tabular}

Fonte: Ffrench-Davis (2005, p. 20)

Do ponto de vista de indicadores sociais a conclusão não é diferente. A tabela 2 mostra alguns desses indicadores. Em termos de percentual da população que se encontra em uma situação de pobreza, nota-se que, em 1980, 40,5\% dessa população estava nessa situação. Em 2004, mesmo com todas as promessas de inclusão social pós-reformas, esse percentual passou para 42,9\%. É bem verdade que grande parte de seu crescimento ocorreu durante a década perdida, mas também é inegável que o discurso neoliberal prometia a resolução desses problemas com a implantação das reformas. ${ }^{31}$

Em termos de salário real médio, observa-se que o poder de compra dos salários em 2004 não chega nem ao patamar do que foi observado em 1980. Quanto à taxa de desemprego, 10\% da população

adotado, o que obviamente daria a políticas sociais compensatórias um caráter meramente concessivo. Para as propostas cepalinas na área social, ver CEPAL (1990) e CEPAL (1997).

${ }^{31}$ Alguns autores neoliberais mais cínicos defendem que é preciso esperar um tempo para maturação das reformas e, portanto, a redução da pobreza só ocorreria com mais tempo. Nesse meio termo, propõe-se o avanço das reformas e a intensificação das já realizadas. Baer e Maloney (1997) fazem exatamente isso. Que duas décadas de neoliberalismo não tenham sido suficientes para obter os resultados prometidos nos traz diretamente a pergunta: será que estaríamos vivos para viver esse tal prazo de maturação? 
latino-americana estavam desempregadas em 2004, frente a 7,3\% em 1990 e 7,7\% em 1980.

Esse desempenho medíocre é conseqüência do aprofundamento dos problemas estruturais em função das reformas neoliberais. Em específico, o processo de abertura externa intensificou a fragilidade financeira e a vulnerabilidade externa das economias. Com um Sistema Financeiro Internacional (SFI) instável, a fragilidade financeira das contas externas se relaciona com a dependência de capital externo para financiá-las; quanto maior essa dependência, maior será a fragilidade financeira. A vulnerabilidade externa, por sua vez, se define pela capacidade de uma economia resistir a choques externos. A primeira cresce quando a segunda é reduzida.

Embora sejam relacionadas, as duas categorias não sinônimas. A maior ou menor dependência de financiamento externo para fechar as contas está relacionada com uma opção nacional/regional de desenvolvimento. A elevação do grau de abertura externa das economias latino-americanas resultou na maior fragilidade financeira. Já a vulnerabilidade externa é uma conseqüência dessa fragilidade. As dimensões dessa vulnerabilidade são as opções de resposta (instrumentos de política econômica) a choques e os custos de enfrentamento (ajuste) dos choques. O processo de abertura externa, em economias periféricas e dependentes, tende a reduzir os instrumentos de política econômica disponíveis para combater instabilidades e crises, assim como tende a aumentar os custos desse enfrentamento.

A política monetária teve o seu grau de autonomia e, portanto, sua capacidade de funcionar como instrumento de resposta a choques, assim como de seguir objetivos internos de política, reduzidos, em virtude do estabelecimento de um piso estrutural para os valores das taxas internas de juros. Com o aprofundamento da liberalização da conta de capital, além da alteração dos marcos regulatórios, as economias dependentes necessitam elevar as taxas internas de juros, em relação a patamares internacionais, como forma de atração de capital externo, necessário para o fechamento das contas. Existe, portanto, um piso no valor das taxas internas de juros, abaixo do qual os capitais tenderiam a se desfazer de suas posições em ativos domésticos, provocando instabilidades e, no limite, crises cambiais.

Essa necessidade de manter elevadas taxas de juros, em virtude das restrições externas também afeta a autonomia da política fiscal. Tomando a relação dívida pública sobre o PIB como um indicador de sustentabilidade da dívida pública, tem-se que essa fração se 
altera conforme a taxa de crescimento do numerador (estoque da dívida pública), em relação à taxa de crescimento do denominador (PIB). As taxas de juros são um dos principais componentes da primeira, enquanto a taxa de crescimento da economia é a segunda. Em razão da necessidade estrutural, aprofundada pelas reformas neoliberais, de taxas reais de juros elevadas, a América Latina vem apresentando sistematicamente taxas reais de juros muito superiores às taxas reais de crescimento. Isso torna imperativa, para manter alguma estabilidade na relação dívida pública/PIB, a obtenção de superávits públicos primários de maneira sustentada, e até crescente, abortando qualquer possibilidade da política fiscal atuar em função de objetivos internos, como produto, emprego e crescimento.

Sendo assim, o grau de autonomia de política econômica, tanto monetária como fiscal, foi consideravelmente reduzido pelo aprofundamento da abertura externa, em função da necessidade de elevadas taxas internas de juros.

Poder-se-ia argumentar que uma adequada escolha de regime cambial resolveria o problema, ou seja, o que se viu anteriormente seria característica de regimes de câmbio (quase) fixos, pois nestes regimes as taxas de juros deveriam variar conforme a movimentação de capitais. Bastaria adotar um regime de câmbio flutuante para que a taxa de câmbio se ajustasse a essa movimentação, liberando a taxa de juros (e a política monetária) para atuar com maior autonomia.

Embora a adoção de regime cambial interfira no grau de autonomia de política, uma escolha "adequada" não resolve o problema estrutural das economias dependentes. Nestas, as restrições externas não são um mero problema de preços relativos, refletidos na taxa de câmbio. Em primeiro lugar, as experiências históricas mostram que a valorização das taxas reais de câmbio ocorreu, nos anos 90, antes da implementação de âncoras cambiais, justamente porque a abertura financeira implementada antes provocou uma forte entrada de capital externo. Em segundo lugar, a restrição externa é estrutural, com maior grau de rigidez e, portanto, relativamente independente do valor da taxa de câmbio. ${ }^{32}$ Isso em função do aumento do grau de abertura externa. A abertura comercial promove dois efeitos. O efeito direto diz respeito à elevação no volume de importações, o que impacta diretamente sobre as contas externas. Um segundo efeito indireto sobre as contas externas se produz quando essa abertura comercial promove uma reestruturação econômica

32 Nesse sentido, o mais importante nem é a escolha do regime cambial, se fixo ou flutuante, mas o compromisso, ainda que não explicitado, com determinado valor da taxa de câmbio, ou melhor, com determinada margem de flutuação para esse valor. 
interna. Como os produtos externos se tornam mais baratos, as encomendas da indústria terminam por se transferir para os bens produzidos externamente. Este processo, depois de algum tempo, leva ao fechamento de unidades produtivas internas, o que lhe justifica a nomenclatura de processo de desubstituição de importações. Assim, a elasticidade da indústria por importações, notadamente por bens intermediários, acaba se elevando. Com isso, qualquer crescimento da renda interna acaba por se refletir em uma elevação das importações e, portanto, em problemas nas contas externas. ${ }^{33}$

A liberalização financeira externa, por sua vez, promove a entrada de capitais externos que, sob uma forma ou outra de entrada, acabam por gerar transferências futuras de juros, lucros e dividendos - isto quando não entram sob a forma de capital especulativo de curto prazo -, implicando a piora da conta de serviços no futuro. Assim, tanto a abertura comercial como a financeira implicam uma elevada necessidade de financiamento externo e, portanto, de altas taxas internas de juros, que promovem os resultados pífios de crescimento na região há pelo menos 15 anos.

\section{Notas Conclusivas para uma Alternativa}

Se isso tem alguma validade, o aprofundamento da restrição externa ao crescimento dessas economias está muito mais ligado às reformas neoliberais, em especial ao processo de abertura externa, do que propriamente a uma escolha de regime cambial.

Uma estratégia econômica alternativa ao neoliberalismo, para ficar apenas na questão do crescimento econômico, deve tratar das condições necessárias para reduzir o grau da restrição externa e elevar a autonomia de suas políticas econômicas, isto é, qualquer alternativa deve buscar a redução da fragilidade financeira e da vulnerabilidade externa, o que implica não tomar as reformas neoliberais como um dado, mas, ao contrário da Nova CEPAL, rechaçá-las, reconstruindo um marco regulatório que impeça a livre mobilidade dos capitais. ${ }^{34}$ Sem essa reconstituição do marco regulatório,

33 É exatamente o que se trata nos modelos pós-keynesianos de restrição externa que trabalham com a lei de Thirlwall. Para isso, ver Thirlwall (1979), Thirlwall (1997), Barbosa Filho (2002) e Jayme Jr. (2001).

34 Pode-se argumentar, no mesmo sentido, pela ruptura com todas as outras reformas neoliberais, se o que se pretende é um crescimento, de fato, com maior eqüidade, mas a falta de espaço nos impede esse tratamento. 
incluindo um maior controle do fluxo de capitais, ${ }^{35}$ qualquer tentativa de redução das taxas de juros levaria a uma fuga de capitais, instabilidade cambial e uma crise de balanço de pagamentos.

Em resumo, a redução do grau de abertura externa, financeiro-cambial e comercial, é um pré-requisito para qualquer estratégia que se proponha alternativa ao neoliberalismo. Se o objetivo é a ruptura com este último, não se pode tomar suas reformas como um dado, procurando gerenciar e direcionar a abertura externa dentro de um endividamento virtuoso, ao mesmo tempo que se procura minimizar os efeitos sociais com políticas sociais compensatórias. A proposta da Nova CEPAL, para ficar apenas na questão da abertura externa, implica condenar-nos a um eterno gerenciamento dos efeitos da abertura, a instabilidade, crise, e restrição externa crescente ao crescimento.

Ruptura e adequação às reformas neoliberais são duas posturas inconciliáveis em uma estratégia de desenvolvimento verdadeiramente alternativa.

\section{Referências}

AKYÜZ, Y. On Financial Openess in Developing Countries. Working Paper. Unctad, Genebra, 1992.

ALMEIDA Fo., N. O Desenvolvimento da América Latina na Perspectiva da CEPAL dos anos 1990: correção de rumos ou mudança de concepção? In: FERRAZ, J. C.: CROCCO, M.; ELIAS, L.A. (Orgs.) Liberalização Econômica e Desenvolvimento: modelos, políticas e restrições. São Paulo: Ed. Futura, 2003.

BAER, W. e MALONEY, W. Neoliberalismo e Distribuição de Renda na América Latina, Revista de Economia Política, v. 17, n. 3, p. 39-62, jul-set, 1997.

BARBOSA FILHO, N. The Balance-of-Payments Constraint: from balanced trade to sustainable debt. Working Paper 2001.06, Center for Economic Policy Analisis, New School University, January, 2002.

BHAGWATI, J. Anatomy and Consequences of Exchange Control Regimes, Cambridge, MA: Ballinger Pub. Co. for NBER, 1978.

BIELSCHOWSKY, R. Cinqüenta Anos de Pensamento na CEPAL - uma resenha. In: BIELSCHOWSKY, R. (Org.) Cinqüenta anos de pensamento na CEPAL. v. 1. São Paulo: Editora Record, 2000.

35 Não apenas como forma de selecionar e tornar gradual o processo de abertura da conta de capital, mas como um dos elementos de uma estratégia de reduzir o grau de abertura externa. 
CANO, W. América Latina: do desenvolvimentismo ao neoliberalismo. In: FIORI, J.L. (Org.) Estados e Moedas no Desenvolvimento das Nações. Petrópolis: Ed. Vozes, 1999.

CANO, W. Soberania e Política Econômica na América Latina. São Paulo: Editora Unesp, 2000.

CAPUTO, O.; PIZARRO, R. Imperialismo, Dependencia y Relaciones Económicas Internacionales. Cuadernos de Estudios Sócio-Económicos, CESO. Universidad de Chile, Chile, 1970.

CEPAL. Transformación Productiva com Equidad: la tarea prioritaria del desarrollo de América Latina y El Caribe en los años noventa. Santiago do Chile, 1990. CEPAL/ONU, 1997.

La Brecha de la Equidad: América Latina, El Caribe y la cumbre social.

América Latina y El Caribe: políticas para mejorar la inserción en la economía mundial. Santiago do Chile, 2. ed. Fondo de Cultura Económica, 1998.

CINTRA, M. A. M. Uma Visão Crítica da Teoria da Repressão Financeira. Campinas: Editora da Unicamp, 1999.

DEMIRGÜÇ-KUNT, A. e DETRAGIACHE, E. Financial Liberalization and Financial Fragility. IMF Working Paper 93/83. Washington D.C., 1998.

DEVLIN, R.; FFRENCH-DAVIS, R.; GRIFFITH-JONES, S. Fluxos de Capital e Desenvolvimento: implicações para as políticas econômicas. In: FFRENCH-DAVIS, R; GRIFFITHJONES, S. (Orgs.) Os Fluxos Financeiros na América Latina: um desafio ao progresso. Rio de Janeiro: Ed. Paz e Terra, 1997.

EICHENGREEN, B.; MUSSA, M.; DELL'ARICCIA, G.; DETRAGIACHE, E.; MILESIFERRETTI, G.M.; TWEEDIE, A. Capital Account Liberalization: theoretical and practical aspects. IMF Occasinal Paper, 172, Washington D.C., 1998.

EICHENGREEN, B.; MUSSA, M.; DELL'ARICCIA, G.; DETRAGIACHE, E.; MILESIFERRETTI, G.M.; TWEEDIE, A Liberalizing Capital Movements: some analytical issues. IMF Economic Issues. n. 17, Washington D.C., 1999.

FANELLI, J.M.; FRENKEL, R. Gradualisme, Traitement de Choc et Périodisation. Revue Tiers Monde, t. XXXV, n. 139, juillet-septembre, 1994.

FFRENCH-DAVIS, R. Macreconomía, Comercio y Finanzas: para reformar las reformas en América Latina, CEPAL/McGraw-Hill, Santiago, 1999.

FFRENCH-DAVIS, R. Reformas para América Latina: después del fundamentalismo neoliberal. Buenos Aires: Siglo XXI Editores, 2005.

FIORI, J.L. Os Moedeiros Falsos. Petrópolis: Ed. Vozes, 1997.

FOXLEY, A. Experimentos Neoliberales en América Latina. México: Fondo de Cultura Económica, 1988.

FURTADO, C. Teoria e Política do Desenvolvimento Econômico. São Paulo: Nova Cultural, 1986.

HAUSMANN, R.; ROJAS-SUÁREZ, L. (Eds.) Volatile Capital Flows: taming impact on Latin America, BID, Washington D.C., 1996.

JAYME Jr., F. G. Balanced-of-Payments Constrained Economic Growth in Brazil, Texto para Discussão, n. 155, Belo Horizonte: CEDEPLAR-UFMG, 2001 
KRUEGER, A. O. Foreign Trade Regimes and Economic Development: liberalization attempts and consequences. Cambridge, MA: Ballinger Pub. Co. for NBER., 1978.

KRUGMAN, P.R. La Nueva Teoría del Comercio Internacional y los Países Menos Desarrollados. El Trimestre Económico, v. LV(1), n. 217, enero-marzo, 1988.

KUCZYNSKI, P.P.; WILLIAMSON, J. Depois do Consenso de Washington: retomando o crescimento e a reforma na América Latina. São Paulo: Ed. Saraiva, 2004.

MARINI, R. M. América Latina: dependência e integração. São Paulo: Ed. Brasil Urgente, 1992.

. La Crisis del Desarrollismo. In: MARINI, R.M.; MILLÁN, M. (Orgs.) La Teoría Social Latinoamericana. Tomo II, Ediciones El Caballito, México, 1994.

McKINNON, R.I. Money and Capital in Economic Development, Washington D.C.: Brookings Institution, 1973.

The Order of Economic Liberalisation: financial control in the transition to a market economy, Baltimore: John Hopkins University Press, 1991.

OCAMPO, J.A. La Reforma del Sistema Financiero Internacional: un debate en marcha, Fondo de Cultura Económica - CEPAL. Chile, 1999.

OSORIO, J. Crítica de la Economía Vulgar: reproducción del capital y dependencia. México: Universidad Autônoma de Zacatecas, Grupo Editorial Miguel Angel Porrua, 2004.

PREBISCH, R. O Desenvolvimento Econômico da América Latina e Alguns de seus Problemas Principais. In: BIELSCHOWSKY, R. (Org.) Cinqüenta anos de pensamento na CEPAL. v. 1. São Paulo: Editora Record, 2000.

RAMOS, J. Un Balance de las Reformas Estructurales en América Latina. Revista de la CEPAL, n. 62, p. 15-38. Santiago, agosto, 1997.

RODDRIGUEZ, O.; BURGEÑO, O.; HOUNIE, A.; PITTALUGA, L. CEPAL: velhas e novas idéias. Economia e Sociedade, n. 5, p. 79-109, Campinas, dezembro 1995.

ROSENTHAL, G. La Evolución de las Ideas Políticas para el Desarrollo. Revista de la Cepal, n.60, p. 7-20, Santiago. Diciembre, 1996.

SOTELO VALENCIA, A. América Latina: de crisis y paradigmas - la teoría de la dependencia em el siglo XXI. México: Plaza y Valdés Editores, 2005.

STIGLITZ, J.E. More Instruments and Broader Goals: moving toward the post-Washington Consensus. Revista de Economia Política, v. 19, n. 1 (73), jan/mar, 1999.

TAYLOR, L. La Apertura Económica: problemas hasta fines del siglo, El Trimestre Económico. v. LV(1), n. 217, p. 67-174, enero-marzo, 1988.

THIRLWALL, A. P. The Balance of Payments Constraint as an Explanation of International Growth Rate Differences. Banca Nazionale del Lavoro Quarterly Review. n. 128, p. 45-53, March, 1979.

Reflections on the Concept of Balance-of-Payments-Constrained Growth. Journal of Post Keynesian Economics. n. 19, p. 377-385, Spring, 1997. 
